\title{
Similarities and differences between intake control mechanisms in pigs, chickens and ruminants
}

\author{
By J. M. Forbes, Department of Animal Physiology and Nutrition, University of \\ Leeds, Leeds LS2 $9 \mathfrak{F T}$
}

The title of this paper presupposes that farm animals do control their voluntary intake but this is really a question of degree. If control were absolute then we would expect, for example, that a fast would be followed by exact compensation when food was made available again; this is not the case, especially with fasts of more than a few hours. However, the fact that some compensation does occur indicates that there is some control and the mechanisms involved appear to be similar for the various groups of farm animals. For control to be exact, the nutrients yielded from the digestive tract would have to meet the requirements of the animal at all times and this could only be achieved by constant nibbling of food. That such continuous nibbling is not a feature of normal feeding behaviour is further evidence of the approximate nature of intake control. Indeed, it would clearly be impossible for an animal offered a single food source to control the intake of each nutrient to meet its requirements unless the composition of the food exactly matched the ratio of nutrients utilized by the animal.

There is not space to attempt to cover the whole of the subject but rather to select some areas where the similarities or differences between the various farm species are of particular interest.

\section{The brain}

Although the brain is the integrating organ, the signals which it uses in making decisions whether or not to eat come from many families of receptors which are monitoring both the internal and external environments. Although the most marked effects come from manipulating the hypothalamus, this is not the only part of the brain which is involved in the control of feeding and it is more appropriate to consider feeding circuits rather than centres. The ventromedial area of the hypothalamus is a particularly critical part of one such circuit, as lesions in this part of the brain cause obesity and hyperphagia in laboratory animals, pigs (e.g. Auffrey, 1969), chickens (e.g. Wright, I 976) and goats (Baile et al. 1969). Although attempts to induce hyperphagia in sheep were not successful (Holmes \& Fraser, 1965; Tarttellin, 1969) this may well have been due to the small area of tissue damaged rather than to any fundamental difference between species.

The ventromedial nucleus controls the secretion of pituitary hormones and in this context it is growth hormone which, if secreted in reduced quantities, will result in low rates of lipolysis, increased demand for energy to support the increased net fat synthesis and a higher level of food intake. There is evidence that rats with ventromedial lesions have impaired growth hormone secretion and also 
become insensitive to negative feedback signals emanating from visceral organs (Novin, 1983). It may be, therefore, that both lipogenesis and food intake are affected directly by ventromedial lesions rather than one being a secondary effect.

It is well known that lesions in the lateral hypothalamus result in aphagia in the rat which is fatal if the animal is not kept alive by force-feeding through the critical period following the operation. Khalaf \& Robinson (1972) found that pigs with electrolytic lesions in the lateral hypothalamus showed aphagia with no signs of recovery when the animals were kept alive by force-feeding. The situation is not clear-cut in chickens; Feldman et al. (1957) and Smith (1969) found that only a proportion of birds with lesions in the lateral hypothalamus showed loss of weight and reduced intake respectively. In the goat, Baile et al. (1968) showed that lesions in the lateral hypothalamus caused hypophagia and a decrease in body-weight.

'Lesioning' is a crude technique and in recent years studies on the role of the brain in the control of food intake have concentrated more on defining the chemical neurotransmitters which might be involved in the feeding circuits. Noradrenaline, a catecholamine transmitter, injected into many sites in the hypothalamus and contiguous areas has been shown to stimulate feeding in laboratory animals but the only comparable work done in the pig shows that isoproterenol (a $\beta$-adrenergic agonist) depresses intake (Jackson \& Robinson, 1971). In chickens the effects of injection of catecholamines into the third ventricle are variable, depending on the strain of bird and whether or not it has been fasted (Denbow et al. 1981, 1983).

It is with the ruminant that most of the work on brain transmitters has been performed. Baile et al. (1972) found that injection of $542 \mathrm{nmol}$ noradrenaline into the lateral ventricle of sheep induced marked hyperphagia for at least $0.5 \mathrm{~h}$, an effect that was blocked by pre-treatment with adrenergic blockers. It was later confirmed that intrahypothalamic injections had similar effects (Baile et al. 1974). Noradrenaline is an $\alpha$-adrenergic agonist; a $\beta$-agonist, isoproterenol, also stimulated intake by sheep but at different sites in the hypothalamus from those at which $\alpha$-agonists were effective. In addition to studies with specific blockers of these agonists, prostaglandins were found to interact, having stimulatory effects at sites which responded to isoproterenol but inhibitory effects when injected into loci at which noradrenaline was stimulatory. This complex subject is reviewed by Baile (1975).

\section{External influences}

Social interactions. The responses of an animal to the presence of other animals vary with the animal's position in the social order. Although dominant pigs exclude subordinate animals from the feed (Baldwin \& Meese, 1979), there is social facilitation of feeding (Hansen et al. 1982) which can lead to increased intake by pigs kept in groups, compared with individual penning (Cole et al. 1967).

The sight and sound of the hen pecking stimulates newly-hatched chicks to peck at food (Savory et al. 1978) and feeding tends to be synchronized in groups of adult birds, but the relative importance of sight (Hughes, 1973) and sound (Clifton, 1979) has not been established. It is a matter of common observation that sheep 
and cattle graze in groups and it has been shown that isolated lambs eat less than those kept in groups (Webster et al. 1972).

Photoperiod. While long photoperiods stimulate growth and food intake in chickens (see Morris, 1968) and ruminants (see Forbes, 1982), the mechanisms involved are different. Whereas in the chicken the primary effect is on intake, and pair-feeding of birds in long and short photoperiods gives no difference in growth, in ruminants the primary effect is on growth, with a secondary effect on intake. The increase in voluntary intake by lambs follows the increased weight gain which occurs under I $6 \mathrm{~h}$ photoperiods, compared with $8 \mathrm{~h}$, rather than preceding it (Forbes et al. 1979) and a pair-feeding regimen still allows increased carcass size under $16 \mathrm{~h}$ photoperiods with less fat and no effect on the weight of the carcass (Forbes $e t$ al. I 98I). Even a I $\mathrm{h}$ 'flash' of light in the middle of the night stimulates the growth and food intake of lambs (Schanbacher \& Crouse, I98I); this type of lighting regimen has no effect on the growth of chickens, although it does affect reproduction.

\section{Visceral influences}

Although the taste, smell and sight of food can influence intake, especially when a choice of foods is available, the main short-term control of feeding is by negative feedback signals from visceral organs.

Distension. Methods ranging from inflation of balloons in the rumen with water (e.g. Balch \& Campling, 1961) to complex simulation modeling of digesta breakdown and flow in the digestive tract (Mertens, 1973) have been used to indicate the importance of stomach distension in ruminant animals fed on roughage diets. Leek \& Harding (1975) have studied the characteristics of the reticulo-ruminal stretch receptors and their projections to the brain. Crop distension in chickens also depresses intake (Richardson, 1970; Shurlock \& Forbes, $\mathrm{I} 98 \mathrm{r} a$ ) and Hodgkiss ( $\mathrm{I} 98 \mathrm{I}$ ) has shown that such distension generates impulses in the vagus nerve.

Distension of the intestines by a balloon has not been attempted, presumably due to the interference with digesta flow, and the relative importance of stretch and osmotic receptors is not certain although the introduction of hypertonic solutions into the duodenum does depress intake in the pig (Houpt, 1982). These effects can be blocked by vagotomy or local anaesthesia and are clearly relayed to the central nervous system by nerves rather than humoral factors. Injection of hypertonic solutions into the duodenum of the chicken also depresses food intake (Shurlock \& Forbes, 1981a).

Chemical stimulation. Glucose, but not amino acids or fat solutions, when injected into the duodenum of fasted pigs had a depressing effect on food intake, suggesting a chemical effect of glucose in addition to the osmotic or stretch effects of this type of treatment (Stephens, I980); again, this is blocked by vagotomy (Stephens \& Heron, 1979). Glucose solution given into the duodenum of free-feeding chickens had much less effect on intake than did solutions of mannitol or potassium chloride (which are not absorbed) of the same osmolality (Shurlock \& 
Forbes, $1981 a$ ), supporting the idea of osmotic or stretch effects. However, overnight fasted birds did reduce their intake in response to glucose infused into the duodenum, presumably due to uptake by the liver. The vagus does not appear to innervate the intestines in the chicken and the intestinal nerve is proving difficult to study (Hodgkiss, I 984 ).

Glucose solutions infused over $3 \mathrm{~h}$ into the hepatic portal vein of fasted chickens at physiological rates resulted in significant reductions in food intake whereas when given into the jugular vein they had no effect (Shurlock \& Forbes, $198 \mathrm{r} b$ ). An amino acid mixture infused into the portal vein also depressed intake (Shurlock \& Forbes, 1984). These effects of portal infusion are blocked by section of the hepatic branch of the vagus nerve (A. A. Rusby, M. H. Anil, P. Chatterjee and J. M. Forbes, unpublished results).

Whereas glucose has been the main product of digestion studied in pigs and poultry, volatile fatty acids have received much more attention in ruminants as they are the major products of digestion. Glucose has no consistent effect on the voluntary intake by ruminants whether given into the rumen, hepatic portal vein, jugular vein or cerebroventricles (see Baile \& Forbes, 1974). It is well-established that acetate affects chemoreceptors in the rumen wall, that its effects can be blocked by local anaesthetics (see Baile \& Forbes, r 974) and that projection to the brain is via the vagus nerve (Leek \& Harding, 1975). However, de Jong (1985) has argued that many experiments have exceeded the normal range of sodium concentration in rumen fluid and blood and he saw no effect on intake when he avoided such changes in his work with goats.

Propionate is not as effective in depressing intake when given into the rumen as it is into the ruminal vein or portal vein. The effect of infusing $1 \cdot 2$ mmol sodium propionate solution/min into the portal vein of sheep was to prevent feeding almost completely, a response which was blocked by local denervation of the liver (Anil \& Forbes, 1980). Section of the splanchnic nerves also blocks the intake-depressing effects of propionate (Anil \& Forbes, 1984) but it seems likely that the vagal route may also be of importance and a vagal pathway from liver to nucleus ambiguus in the medulla oblongata has been demonstrated (H. Anil, P. Chatterjee and J. M. Forbes, unpublished results). Propionate is gluconeogenic and is taken up by the liver; the effect of propionate on food intake of ruminants is, therefore, presumably analogous to that of glucose in the simple-stomached animal.

Temperature. Intake and digestion of food leads to increased heat production by the viscera, especially in the ruminant animal. Rawson \& Quick (1971) demonstrated the existence of temperature receptors in the abdomen of sheep with afferent pathways in the splanchnic nerve and it may be that it is by this route that the effects of rumen cooling (Bhattacharya $\&$ Warner, 1968) or heating (Gengler et al. 1970) have their effects (stimulatory and inhibitory respectively) on intake. There has been no equivalent work with pigs or poultry. 


\section{Body fatness}

Most adults of many species maintain a relatively constant body-weight, defending it against changes in dietary energy concentration or energy expenditure by appropriate changes in voluntary intake. That this defence is of fat rather than of body-weight is demonstrated by the work of Leibelt et al. (1965) in which removal from rats of inguinal fat led to hyperphagia until that amount of fat was replaced; there is no evidence of equivalent compensation for removal of muscle, for example. The identity of the feedback from adipose tissue which informs the brain of the amount of fat in the body has thus far remained undiscovered. The most recent hypothesis is that the concentration of insulin in the cerebrospinal fluid gives an integrated picture of blood insulin levels, which become elevated as animals fatten (Porte \& Woods, $198 \mathrm{r}$ ). Infusion of insulin at very low rates into the cerebroventricles of baboons causes a depression in their food intake (Woods et al. 1979).

Whereas man, rat, dog and many other species seem to be able to regulate their fatness, this is not true of domesticated pigs, cattle or sheep. These animals continue to gain fat until they are very obese if given free access to high-quality feeds. The pig is a proverbial glutton, while Blaxter et al. (1982) have observed that sheep of lowland-breeding fed ad lib. on a complete feed did not plateau in weight until they reached $160 \mathrm{~kg}$ and their carcass gain contained $600 \mathrm{~g} \mathrm{fat} / \mathrm{kg}$. Friesian cows also continued to gain weight beyond $700 \mathrm{~kg}$ when fed $a d$ lib. and not remated (Monteiro, 1972). It is likely that selection for rapid growth, without regard for carcass composition, has resulted either in a reduction in the level of the feedback signal from fat or in a relative insensitivity to that signal(s) on the part of the brain.

Although it had been suggested that the eventual plateau in fatness in the ruminant animal was due to physical restriction of gut capacity, it is now clear that there are also substantial metabolic effects of fat on intake. Orr (1977) found that sheep which were purposely made either fat or thin by appropriate levels of feeding increased their intake in response to reductions in dietary metabolizable energy (ME) concentration, irrespective of fatness, even though the level of intake was lower in fat animals. Thus the fat sheep were still controlling their ME intake, but at a lower level than the lean sheep. As adipose cells become more replete they decrease their rate of fat synthesis and increase lipolysis. Perhaps the high levels of fatty acids coupled with high circulating insulin are detected and used to modulate voluntary intake.

\section{Additivity of controlling signals}

It has been implied above that no single physiological signal is likely to be sufficient to stop feeding entirely. If, however, the various signals are interpreted as a whole then numerous small changes, such as might occur during a spontaneous meal, might be sufficient to induce and maintain satiety. We have 
tested the theory that negative feedback signals are additive, both in chickens and in sheep.

Infusion of glucose solutions into the hepatic portal vein of chickens depresses intake, as does distension of the crop with hypertonic glucose solution; the effects of these two treatments given in combination are additive as shown by Shurlock \& Forbes $(\mathrm{r} 98 \mathrm{r} b)$. Mixtures of glucose and amino acids infused into the portal vein depress intake to an extent equal to the sum of the two given separately (Shurlock \& Forbes, 1984) and the same is true for glucose and lysine (A. A. Rusby and J. M. Forbes, unpublished results).

In the sheep, infusion of propionate into the portal vein or distension of a balloon in the rumen have depressing effects on food intake which are additive with those of intraruminal infusion of acetate, so long as the treatments are within the physiological range (Adams \& Forbes, 198I). With two such treatments given at supra-physiological levels, however, intake is not affected as much as would be predicted from the effects of the individual treatments; this was also a feature of the results with chickens and it presumably requires more than just two families of receptors to be stimulated, however strongly, in order to induce complete satiety.

Not only are the effects of acetate additive with those of rumen distension or propionate but also with the intake-stimulating effect of noradrenaline injected intracerebroventricularly (Aydintug \& Forbes, 1985). While $4 \mathrm{mmol}$ sodium acetate/min depressed intake by $199 \mathrm{~g}$ during a $3 \mathrm{~h}$ infusion into the rumen (from 217 to $18 \mathrm{~g}$ ) and $542 \mathrm{nmol}$ noradrenaline injected into the lateral ventricles stimulated intake by $75 \mathrm{~g}$ (to $292 \mathrm{~g}$ ), noradrenaline also increased intake by $80 \mathrm{~g}$ (to $98 \mathrm{~g}$ ) when given $\mathrm{I} h$ after the start of the acetate infusion. There are also additive effects on feeding in chickens when melatonin, which causes aphagia when given alone, is given in combination with triiodothyronine, which stimulates intake (Bermudez et al. 1983).

\section{Conclusions}

There are obvious differences in the relative importance of the various controlling mechanisms for intake between pigs, chickens, sheep and cattle. In particular, the slow digestion of roughage feeds in the rumen makes signals of physical distension a particularly important feedback in the ruminant animal. Severe dilution of the diet also depresses intake in simple-stomached animals, however, and there is no absolute difference in the control mechanisms involved.

The integration of negative and positive effects of intake appears to be accomplished in an additive manner. We still need to know the constants of proportionality for the various signals and much quantitative work remains to be done, especially with lactating cows.

\section{REFERENCES}

Adams, G. B. \& Forbes, J. M. (1981). Proceedings of the Nutrition Society 40, 44 A.

Anil, M. H. \& Forbes, J. M. (1980). Fournal of Physiology 298, 407-414.

Anil, M. H. \& Forbes, J. M. (1984). Canadian fournal of Animal Science 64, Suppl., 343-344. 
Auffrey, P. (1969). Annales de Biologie Animale, Biochimie et Biophysique 9, 513-526.

Aydintug, S. \& Forbes, J. M. (1985). Proceedings of the Nutrition Society 44, 48A.

Baile, C. A. (1975). In Digestion and Metabolism in the Ruminant, pp. 333-350 [1. W. McDonald and A. C. I. Warner, editors]. Armidale: University of New England Press.

Baile, C. A. \& Forbes, J. M. (1974). Physiological Reviews 54, I60-2 I4.

Baile, C. A., Mahoney, A. W. \& Mayer, J. (1968). Journal of Dairy Science 51, 1474-1480.

Baile, C. A., Martin, F. H., Simpson, C. W., Forbes, J. M. \& Beyea, J. S. (1974). Fournal of Dairy Science 57, 68-80.

Baile, C. A., Mayer, J., Mahoney, A. W. \& McLaughlin, C. L. (1969). Fournal of Dairy Science 52, 101-Iog.

Baile, C. A., Simpson, C. W., Krabill, L. F. \& Martin, F. H. (1972). Life Sciences 1 1, 661-668.

Balch, C. C. \& Campling, R. C. (1961). British fournal of Nutrition 15, 523-530.

Baldwin, B. A. \& Meese, G. B. (1979). Animal Behaviour 27, 947-957.

Bermudez, F. F., Forbes, J. M. \& Injidi, M. H. (1983). Fournal of Physiology 337, 19-27.

Bhattacharya, A. N. \& Warner, R. G. (1968). Fournal of Dairy Science 51 , I481-1489.

Blaxter, K. L., Fowler, V. R. \& Gill, J. C. (1982). Fournal of Agricultural Science, Cambridge 98, 405-420.

Clifton, P. G. (1979). Animal Behaviour 27, 829-832.

Cole, D. J. A., Duckworth, J. E. \& Holmes, W. (1967). Animal Production 9, 141-149.

de Jong, A. (1985). Control of Digestion and Metabolism in the Ruminant. Proceedings of the VI International Symposium on Ruminant Physiology, Banff, 1984 .

Denbow, D. M., Cherry, J. A., Siegal, P. B. \& Van Krey, H. P. (1981). Physiology and Behavior $27,265-269$.

Denbow, D. M., Van Krey, H. P., Lacy, M. P. \& Dietrick, T. J. (1983). Physiology and Behavior 31, 85-90.

Feldman, S. E., Larsson, S., Dimick, M. K. \& Lepkovsky, S. (1957). American fournal of Physiology 191, 259-261.

Forbes, J. M. (1982). Livestock Production Science 9, 361-374.

Forbes, J. M., Brown, W. B., Al-Banna, A. G. M. \& Jones, R. (1981). Animal Production 32, 23-28.

Forbes, J. M., El Shahat, A. A., Jones, R., Duncan, J. G. S. \& Boaz, T. G. (1979). Animal Production 29, 33-42.

Gengler, W. R., Martz, F. A., Johnson, H. D., Krause, G. F. \& Hahn, L. (1970). Journal of Dairy Science 53, 434-437.

Hansen, L. L., Hagelso, A. M. \& Madsen, A. (1982). Applied Animal Ethology 8, 307-333.

Hodgkiss, J. P. (I 981). Comparative Biochemistry and Physiology 70A, 73-78.

Hodgkiss, J. P. (1984). Fournal of Physiology 349, 36P.

Holmes, E. G. \& Fraser, F. J. (1965). Australian fournal of Biological Science 18, 345-352.

Houpt, T. R. (1982). In Digestive Physiology in the Pig, pp. 17-28 [J. L. Laplace, T. Corring and A. Rerat, editors]. Paris: INRA.

Hughes, H. (1973). British Poultry Science 12, 359-366.

Jackson, H. M. \& Robinson, D. W. (1971). British Veterinary fournal 127, li-liii.

Khalaf, F. \& Robinson, D. W. (1972). Research in Veterinary Science 1 3, 1-4.

Leek, B. F. \& Harding, R. H. (1975). In Digestion and Metabolism in the Ruminant, pp. 60-76 [I. W. McDonald and A. C. I. Warner, editors]. Armidale: University of New England Press.

Leibelt, R. A., Nicholson, N. \& Ichinoe, S. (1965). Annals of the New York Academy of Science $13^{1}, 559-582$.

Mertens, D. R. (1973). Applications of theoretical mathematical models to cell wall digestion and forage intake in ruminants. PhD Thesis, Cornell University, New York.

Monteiro, L. S. (1972). Animal Production 14, 263-281.

Morris, T. R. (1968). In Environmental Control of Poultry Production, pp. 15-39 [T. C. Carter, editor]. Edinburgh: British Poultry Science.

Novin, D. (1983). Journal of the Autonomic Nervous System 9, 233-246.

Orr, R. M. (1977). A study on the role of body fatness in the control of voluntary feed intake in sheep. PhD Thesis, University of Edinburgh.

Porte, D. \& Woods, S. C. (1981). Diabetologia 20, 274-280.

Rawson, R. O. \& Quick, K. P. (1971). Pflugers Archivs 330, 362-365.

Richardson, A. J. (1970). Animal Behaviour 18, 633-639. 
Schanbacher, B. D. \& Crouse, J. D. (I981). American fournal of Physiology 24I, EI -E 5 .

Shurlock, T. G. H. \& Forbes, J. M. (1981a). British Poultry Science 22, 323-331.

Shurlock, T. G. H. \& Forbes, J. M. (1981 b). British Poultry Science 22, 333-346.

Shurlock, T. G. H. \& Forbes, J. M. (1984). British Poultry Science 25, 303-308.

Smith, C. J. V. ( 1 969). Poultry Science 48, 475-477.

Stephens, D. B. (1 980). Fournal of Physiology 299, 453-463.

Stephens, D. B. \& Heron, F. (1 979). Proceedings of the Nutrition Society $38,46 \mathrm{~A}$.

Tarttellin, M. F. (1969). The physiology of the ventromedial hypothalamus of the sheep with special reference to food and water intake. PhD Thesis, University of London.

Webster, A. J. F., Smith, J. S. \& Brockway, J. M. (1972). Animal Production I5, 189-20I.

Woods, S. C., Lotter, E. C., McKay, L. D. \& Porte, D. (1979). Nature 282, 503-505.

Wright, P. (1976). In Neural and Endocrine Aspects of Behaviour in Birds, pp. 319-349 [P. Wright and P. G. Caryl, editors]. Amsterdam: Elsevier. 